\title{
LATEWOOD CHRONOLOGY DEVELOPMENT FOR SUMMER-MOISTURE RECONSTRUCTION IN THE US SOUTHWEST
}

\author{
DANIEL GRIFFIN ${ }^{1,2 *}$, DAVID M. MEKO ${ }^{1}$, RAMZI TOUCHAN ${ }^{1}$, STEVEN W. LEAVITT $^{1}$, and \\ CONNIE A. WOODHOUSE ${ }^{1,2}$ \\ ${ }^{1}$ Laboratory of Tree-Ring Research, 105 W. Stadium, University of Arizona, Tucson, AZ, 85721, USA \\ ${ }^{2}$ School of Geography and Development, 409 Harvill Building, University of Arizona, Tucson, AZ, 85721, USA
}

\begin{abstract}
Tree-ring studies have demonstrated that conifer latewood measurements contain information on long-term North American monsoon (NAM) variability, a hydroclimatic feature of great importance to plants, animals, and human society in the US Southwest. This paper explores datatreatment options for developing latewood chronologies aimed at NAM reconstruction. Archived wood samples for five Douglas-fir (Pseudotsuga menziesii, Mirb. Franco) sites in southeastern Arizona are augmented with new collections. The combined dataset is analyzed along with time series of regionally averaged observed precipitation to quantify the strength of regional precipitation signal in latewood time series and to identify ways of increasing the signal strength. Analysis addresses the signal strength influences of including or excluding "false" latewood bands in the nominal "latewood" portion of the ring, the necessary adjustment of latewood width for statistical dependence on antecedent earlywood width, and tree age. Results suggest that adjusted latewood width chronologies from individual sites can explain around $30 \%$ of the variance of regional summer (July-August) precipitation-increasing to more than $50 \%$ with use of multiple chronologies. This assessment is fairly insensitive to the treatment of false latewood bands (in intra-annual width and $\delta^{13} \mathrm{C}$ variables), and to whether latewood-width is adjusted for dependence on earlywood-width at the core or site level. Considerations for operational chronology development in future studies are (1) large tree-to-tree differences in moisture signal, (2) occasional nonlinearity in EW-LW dependence, and (3) extremely narrow and invariant latewood width in outer portions of some cores. A protocol for chronology development addressing these considerations is suggested.
\end{abstract}

Keywords: Latewood, chronology development, Douglas-fir, Pseudotsuga menziesii, North American monsoon, summer precipitation, Arizona, false rings, carbon isotopes.

\section{INTRODUCTION}

The North American monsoon (NAM) is a predominant climatic feature in northern Mexico and the US Southwest characterized by large-scale changes in pressure, wind, and water vapor that translate to local-scale convective thunderstorms across the region during the warm season (Adams and Comrie 1997). The NAM contributes up to $60 \%$ of the annual precipitation in parts of the US Southwest, and is a critical factor in maintaining the region's ecosystems that rely on a bimodal precipitation regime. The NAM influences natural fire dynamics (Swetnam and Betancourt 1998; Grissino-Mayer and Swetnam 2000) and modu-

*Corresponding author: dgriffin@email.arizona.edu lates demand for urban and agricultural water supplies (Ray et al. 2007). Spatiotemporal variability in monsoon precipitation has been the topic of extensive research in recent decades (e.g. Carleton and Carpenter 1990; Douglas et al. 1993; Comrie and Glenn 1998; Gutzler 2000; Higgins and Shi 2000; Castro et al. 2001; Zhu et al. 2005; Higgins and Gochis 2007; Liebmann et al. 2008; Turrent and Cavazos 2009), and robust information on monsoon variability has implications for natural resources management (Ray et al. 2007). The research described here is part of a larger study aimed at development of the first large-scale network of NAM precipitation-sensitive chronologies in the US Southwest.

Although most dendroclimatic studies in the interior Southwest have targeted cool-season or 
annual precipitation (e.g. D'Arrigo and Jacoby 1991; Grissino-Mayer 1996; Meko 1997; Woodhouse and Meko 1997; Ni et al. 2002; Cleaveland et al. 2003; Salzer and Kipfmueller 2005; Villanueva-Diaz et al. 2007; Touchan et al. 2010), dendrochronologists have long recognized the potential of intra-annual ring-width (hereafter 'partial width') measurement for summer-season climate information (Douglass 1919; Schulman 1942, 1951; Winter 1976; Cleaveland 1986, 1988). Several recent southwestern studies have reconstructed monsoon-specific moisture conditions using measurements of "earlywood width" (EW) and "latewood width" (LW). For this work, earlywood is defined as the lighter-colored, lessdense component of the annual ring, whereas latewood is defined as the darker-colored, moredense component that is visually discernable and often characterized by an abrupt anatomical transition from antecedent earlywood.

Partial-width measurements can be rapidly obtained by well-trained technicians using a Velmex measurement system and simple visual criteria for determination of the boundary between EW and LW width. This is an attractive alternative to methods such as X-ray densitometry (Schweingruber et al. 1978; Cleaveland 1986, 1988) and reflected light densitometry (Sheppard and Wiedenhoeft 2007; Babst et al. 2009), which require extensive sample preparation and are challenged by the micro-rings and missing rings that are common in semi-arid sites around the Southwest.

Meko and Baisan (2001) applied a binary classification-tree model to categorize summers as wet or dry from adjusted latewood-width (hereafter, $\mathrm{LW}_{\mathrm{a}}$ ) index chronologies from conifers in southeastern Arizona. The "adjustment" consisted of removing the LW's systematic dependence on antecedent EW using linear regression, isolating the variability unique to the $\mathrm{LW}$, which substantially enhanced the summer moisture signal. Therrell et al. (2002) showed that LW chronologies in Mexico contain a signal related to largescale monsoon onset. Stahle et al. (2009) reconstructed 2,136 years of July precipitation in northwestern New Mexico from a single $\mathrm{LW}_{\mathrm{a}}$ chronology. Leavitt et al. $(2002,2011)$ found a NAM moisture signal in stable carbon $\left({ }^{13} \mathrm{C} /{ }^{12} \mathrm{C}\right.$; hereafter $\delta^{13} \mathrm{C}$ ) isotope analysis of latewood cellulose. Sheppard and Wiedenhoeft (2007) demonstrated the utility of reflected light analysis in extracting summer-moisture signal from the latewood of conifers in New Mexico.

Previous studies raise several questions about the operational large-scale application of latewood measurements to summer-rainfall reconstruction and NAM analysis. The first regards how the partial-width components should be defined for this objective when distinct intra-annual wooddensity variations known as "false rings" are present (Figure 1). All known studies are consistent in using the first false latewood band as a marker separating EW and LW, but disagree on assignment of the band itself to EW or LW. Schulman (1951:25) described the phenomena but was not precisely clear about whether the first latewood band should be included in the EW or LW: "A somewhat arbitrary criterion had to be set up for the amount of latewood in the numerous rings which included false bands. Because experience elsewhere in the Southwest had indicated that false rings were related to the July and, to a lesser extent, the August rains, and because the onset of normal latewood growth in the timber conifers is in July, all growth following the first latewood cells was classed as latewood, no matter how apparently complete the return to earlywood type before the final cells of the season were laid down". Winter (1976:46) followed Schulman's 1951 "suggestion" and measured LW "from the earliest occurrence of small, dense cells". Stahle et al. (2000) and Stahle et al. (2009:3734) mark the EW-LW boundary "at the first onset of lumen contraction (i.e. all false rings are measured as part of the LW)". In contrast, Meko and Baisan (2001, personal communication) and Leavitt et al. (2002) include the first false latewood band in the EW, citing Arizona studies that attribute false-ring formation to moisture changes from the cool season through the routinely dry "fore-summer" period of May-June that precedes the onset of the summer monsoon (Douglass 1919; Zahner 1963; Fritts 2001; Baisan and Swetnam 1994). The two partial-width marking rules are referred to hereafter as MB2001 (Meko and Baisan 2001) and ST2009 (Stahle et al. 2009). 


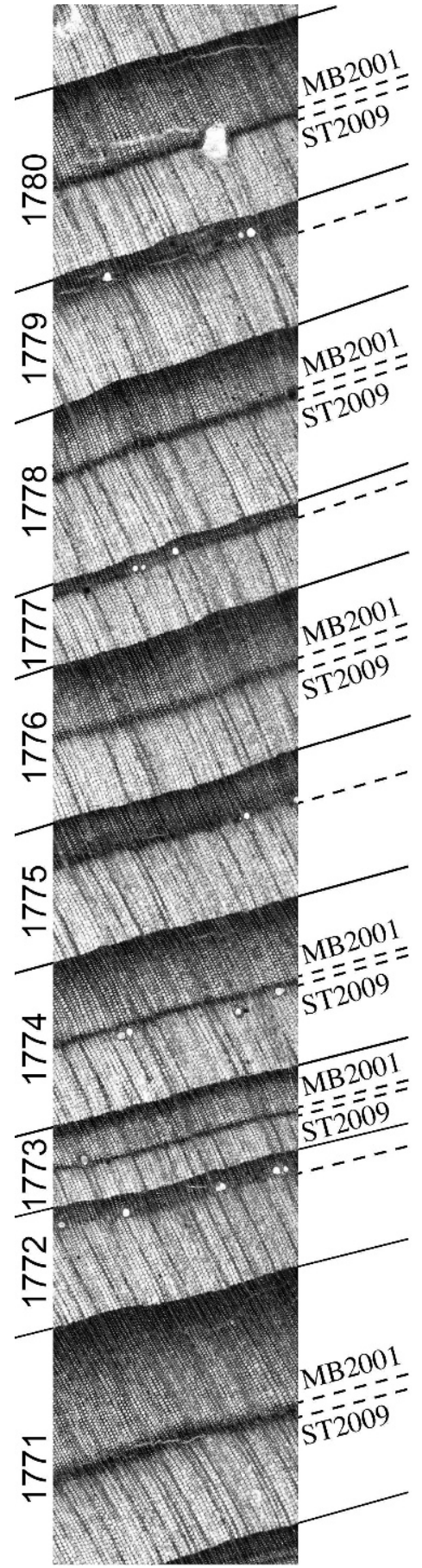

Figure 1. Photomicrograph illustrating growth rings for the years 1771-1780 on a Douglas-fir increment core from site PRM. Solid lines indicate annual boundaries and dashed lines indicate the visually identified EW-LW boundary as marked by Meko and Baisan (2001) ("MB2001") and Stahle et al. (2009)
A second question relates to the appropriate procedure for adjusting LW for dependence on antecedent EW. Meko and Baisan (2001) found that removal of this dependence is key to the extraction of a summer-rainfall signal, and did so by linear regression of site-chronology LW indices on site-chronology EW indices. The same approach was followed by Stahle et al. (2009). Scatterplots of LW index on EW index for individual cores from conifers in Arizona have revealed much tree-to-tree variation in the dependence. Improved site chronologies for summer-rainfall reconstruction might therefore be possible if the dependence of LW on EW was modeled and removed at the core-level instead of the site-level.

A third question is the possible importance of tree age to strength of the summer-moisture signal in LW. LW, like total width (TW), typically decreases with increasing tree age. The decrease of LW with age can be extremely steep, however, and the LW can become extremely narrow and nearly invariable from year-to-year in the outer portions of some cores. Winter (1976), Meko and Baisan (2001), Therrell et al. (2002), and Stahle et al. (2009) recognized this problem and addressed it by excluding the outside segments of problematic cores from LW chronology development; these authors advocate including young to middle-aged trees (e.g. 100-250 yr-old) throughout the chronology. Until now, however, no attempt has been made to quantify the age-dependence of the LW signal for summer moisture, or to develop an objective procedure for screening and truncation of problematic cores.

In the paper we address the challenges described above with observed precipitation and tree-ring data from selected Douglas-fir (Pseudotsuga menziesii, Mirb. Franco) sites in southeastern Arizona. We quantify the strength of summermoisture signal at the level of the individual core and site chronology, and assess the sensitivity of

$\leftarrow$

("ST2009"). Both use the earliest false ring to delineate the EWLW boundary, the former including the first false latewood band in the EW measurement, and the latter including it in the LW measurement. 


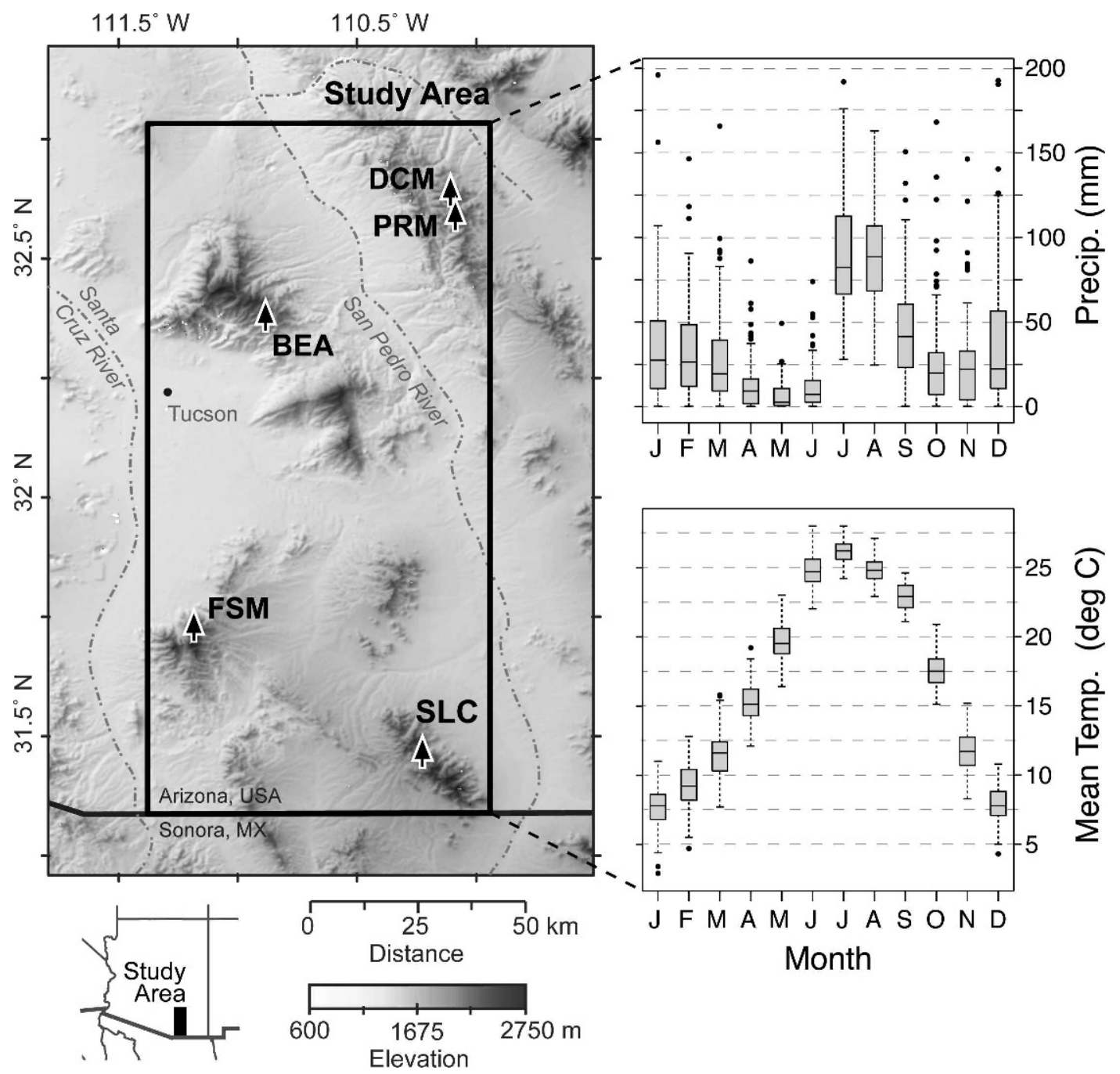

Figure 2. Site locations and regional climatogram. Map shows the study area in southeastern Arizona, including the locations of the tree-ring collections measured for partial width (DCM, FSM, PRM, SLC) and for $\delta^{13} \mathrm{C}$ (BEA). Black box indicates the area for which PRISM climate data were obtained for sensitivity analyses. Climatogram uses box and whisker plots to illustrate the distribution of monthly precipitation and temperature for the period 1895-2008. Each box bounds the interquartile range with the median illustrated as the horizontal line. Whiskers extend to the data within $1.5 \mathrm{q}$ of the box where $\mathrm{q}$ is the interquartile range. Black dots are outliers.

the signal to (1) rule in marking of the earlywoodlatewood boundary, (2) adjustment of LW for dependence on antecedent EW at the core level versus site level, and (3) tree age. We also propose a protocol for objective identification and screening of problematic LW series. A small component of the work addresses the sensitivity of the latewood cellulose $\delta^{13} \mathrm{C}$ relative to the rule used in marking the earlywood-latewood boundary.

\section{DATA AND METHODS}

\section{Tree-Ring Data}

Douglas-fir increment-core collections from five sites in southeastern Arizona are used in this study (Figure 2; Table 1). Partial ring widths were analyzed for four collections (Table 1; DCM, PRM, FSM, SLC). Samples were collected from four trees for latewood $\delta^{13} \mathrm{C}$ at the fifth site, BEA. 
Table 1. Tree-ring site information.

\begin{tabular}{|c|c|c|c|c|c|c|c|c|}
\hline $\begin{array}{c}\text { Site } \\
\text { Code }^{\mathrm{a}}\end{array}$ & Site Name & $\begin{array}{c}\text { Latitude } \\
\left({ }^{\circ} \mathrm{N}\right)\end{array}$ & $\begin{array}{c}\text { Longitude } \\
\left({ }^{\circ} \mathrm{W}\right)\end{array}$ & $\begin{array}{c}\text { Elevation } \\
\text { (M) }\end{array}$ & $\begin{array}{c}\text { Variable } \\
\text { Measured }\end{array}$ & $\begin{array}{c}\text { No. of } \\
\text { Trees }\end{array}$ & $\begin{array}{c}\text { No. of } \\
\text { Radii }\end{array}$ & $\operatorname{MSSL}^{\mathrm{b}}$ \\
\hline FSM & Florida Saddle & 31.723 & 110.839 & 2,385 & partial width & 55 & 94 & 190 \\
\hline DCM & Douglas Canyon & 32.627 & 110.298 & 2,074 & partial width & 41 & 69 & 150 \\
\hline PRM & Paddy's River & 32.586 & 110.283 & 2,252 & partial width & 40 & 71 & 185 \\
\hline SLC & Scheelite Canyon & 31.461 & 110.355 & 1,812 & partial width & 48 & 72 & 135 \\
\hline BEA & Bear Canyon & 32.377 & 110.685 & 1,877 & latewood $\delta^{13} \mathrm{C}$ & 4 & 8 & 10 \\
\hline
\end{tabular}

a Three letter code, as in Figure 2.

${ }^{\mathrm{b}}$ Mean sample segment length (years).

The wood samples used for width analysis are a combination of new collections made in the spring of 2009 and archived wood specimens housed at the Laboratory of Tree-Ring Research from previous dendroclimatic studies. Middle-aged (i.e. 100 to $250 \mathrm{yr}$-old) and young trees (i.e. less than $100 \mathrm{yr}$-old) were specifically included in the new collections to evaluate the potential influence of tree age on moisture sensitivity of LW.

Specimens were prepared and crossdated with standard dendrochronological methods (e.g. Stokes and Smiley 1996). EW, LW, and TW were measured to an accuracy of $0.001 \mathrm{~mm}$ with a Velmex system using both the MB2001 and

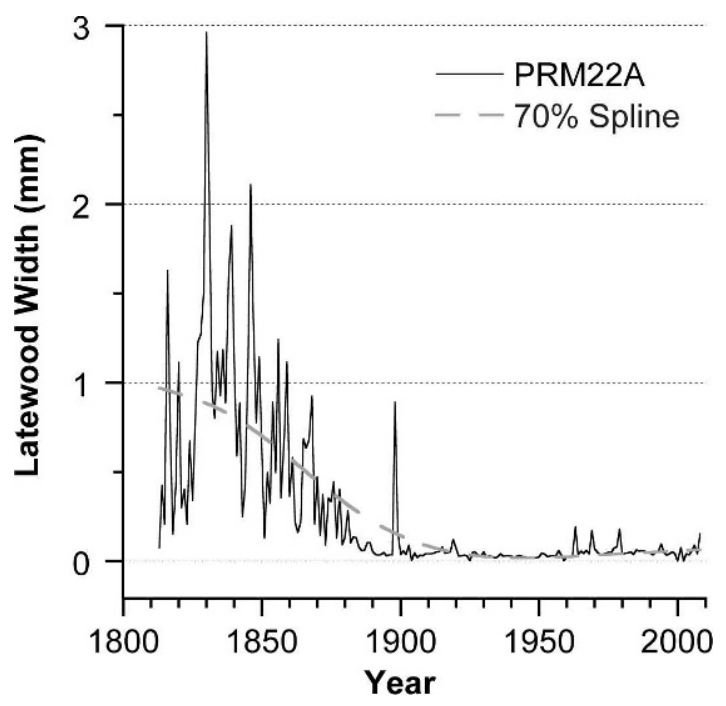

Figure 3. Latewood width measurement time series (core PRM22A) that was dropped from the study because the latewood width was thin, little-varying, and poorly correlated with the other series from the site. Dashed line is fitted $70 \%$ spline (Cook and Peters 1981).
ST2009 rules for the EW-LW boundary. The boundary was determined optically under the microscope by measuring technicians guided by templates of microphotographs illustrating the MB2001 and ST2009 marking rules (e.g. Figure 1). Crossdating and measurement accuracy were verified with program COFECHA (Holmes 1983; Grissino-Mayer 2001). Prior to standardization, as described by Therrell et al. (2002) and Stahle et al. (2009), precisely dated LW segments and series that were identified by COFECHA as exhibiting low correlation with the other series were excluded from the subsequently calculated site-level chronologies.

The archive specimens had previously been crossdated, but required measurement of partial widths. Archive specimens were selected that exhibited visually strong LW variability over time, and the outer portions of cores with extremely thin, relatively invariant latewood width or with a high frequency of missing rings after 1950 were excluded from this analysis (Figure 3). This screening step frequently identified the same problematic cores as in the COFECHA analysis. For example, the core illustrated in Figure 3 also has a drop in 50-year windowed correlations with its COFECHA master from 0.70 before 1899 to less than 0.11 after 1925 .

Measured ring-width series of TW, EW and LW were detrended with a cubic smoothing spline whose frequency response is 0.5 at a wavelength equal to $70 \%$ of the length of the measured series (Cook and Peters 1981). Core indices were computed as the ratio of measured width to the corresponding value of this " $70 \%$ spline". Pooled autocorrelation was modeled and removed from 
the individual EW and LW index time series by autoregressive modeling (Box and Jenkins 1976; Meko 1981) to produce "residual" core-level indices.

Adjusted-LW index was computed as in previous studies (Meko and Baisan 2001; Stahle et al. 2009) as the residual from a linear regression of LW index on antecedent EW index. Because exploratory scatter plots of LW index on EW index occasionally exhibited pronounced curvature, we modified this procedure to allow a quadratic term to enter the regression, as long as the resulting regression coefficients on both the linear and quadratic term were positive. This constraint is consistent with the observation from individual scatter plots that organized patterns of curvature were typically concave-upward. If either of the estimated regression coefficients were negative, a purely linear model was used for the adjustment, and in that case the slope of the fitted line was not restricted to be positive.

Robust bi-weight mean chronologies of TW, EW, LW and adjusted LW were computed for each site by averaging over cores (Cook et al. 1990). To summarize the strength of common growth signal, the effective chronology signal (Briffa and Jones 1990; equation 3.43) was calculated for each version of the chronology. Adequacy of sample size for capturing the hypothetical population growth signal was assessed by the expressed population signal (EPS; Briffa 1984; Wigley et al. 1984); a threshold EPS of 0.85 was used to delineate the "critical year", when sample depth becomes adequate for capturing the population signal.

Standardization by the procedure just described revealed two problematic features of LW that required special treatment for some cores. First is the rare (only 3 of 306 cores) phenomenon of the fitted $70 \%$ spline dipping to zero or below in response to an especially steep decline in LW. For such series the ring-width series was truncated to end 10 years before the growth curve dropped below zero, and the series was re-fit with a 100year spline (Cook and Peters 1981).

The second problematic feature of some LW series was clear tracking of a known recent lowfrequency climate fluctuation by the $70 \%$-spline growth curve when fit to short ring-width series from the young-tree samples: the spline for series beginning in the 1940s or 1950s typically had a strong upward trend out of the well-documented and persistent 1950s drought (Thomas 1962). Such short samples, though probably not relevant to operational climate reconstruction, are important to the assessment of possible age-dependence in climate signal. To avoid removing this predominant climate signal in standardization, we fit such series with a horizontal line at the mean ring-width rather than with a $70 \%$ spline.

The $\delta^{13} \mathrm{C}$ analysis was limited to a short sequence of ten rings (1999-2008) from four young (55 to 80 yr-old) trees at site BEA. Latewood cellulose was isolated for $\delta^{13} \mathrm{C}$ analysis with the techniques described by Leavitt et al. (2002). Increment cores were split longitudinally to provide two samples (MB2001 and ST2009 marking rules) from each core for each year. For each tree, latewood cellulose samples pooled from two cores were combusted to $\mathrm{CO}_{2}$ in an elemental analyzer, which was introduced into a Finnigan Delta-Plus mass-spectrometer in flow-through mode at the Environmental Isotope Laboratory, University of Arizona, with procedure and standards as described in Panyushkina et al. (2008). Analytical precision for repeat analysis of the working standard (highly-homogenized commercial cellulose) is $c a$. $0.09 \%$. The $\delta^{13} \mathrm{C}$ series, though too short for rigorous statistical analysis, were examined for any large and systematic differences in $\delta^{13} \mathrm{C}$ when partial-width boundaries are delineated by the MB2001 and ST2009 marking rules. Three of the 80 samples were lost in preparation and analysis, so comparison of the MB2001 and ST2009 marking rules was possible for 37 of the 40 pairs.

\section{Climate Data}

Monthly total precipitation and mean temperature data used in this study are from the Parameter-elevation Regressions on Independent Slopes Model (PRISM) gridded dataset, as described in detail by Daly et al. (2008). PRISM data for the period 1895-2008 were obtained from the Western Climate Mapping Initiative (WestMap) 
website (http://www.cefa.dri.edu/Westmap/; last accessed February 27, 2011) for the rectangular area bound by the northwestern coordinate of $32.784^{\circ} \mathrm{N}, 110.939^{\circ} \mathrm{W}$ and the southeastern coordinate of $31.339^{\circ} \mathrm{N}, 110.221^{\circ} \mathrm{W}$, which encompasses the four mountain ranges from which the treering data originate (Figure 2). The climatogram presented in Figure 2 illustrates the range of monthly precipitation and mean monthly temperature for this region in the period 1895-2008. Note the distinct mode of precipitation in July-August related to the North American monsoon, and the warm dry fore-summer period of May-June immediately preceding monsoon onset in the region.

\section{Sensitivity Analysis}

Correlation analysis was used to summarize the seasonal precipitation signal in total-width and partial-width indices, including the sensitivity of the signal to several data-processing options in chronology development. For each of the four partial width sites, cool-season (October-April) and summer (July-August) precipitation sums, 1896-2008, were correlated with four different versions of residual site chronologies of TW, EW and LW computed by combinations of the following options:

1. MB2001 or ST2009 rule for marking the boundary between earlywood and latewood

2. Adjustment of LW for dependence on antecedent EW at the individual-core level or the site level.

Correlations between July-August precipitation and adjusted-LW indices for individual cores were also computed to summarize the variability in strength of summer moisture signal among trees. The analysis was restricted to the set of partial-width measurements completed with the MB2001 marking rule. Correlations were computed for the period 1937-1986, a fifty-year period common to the greatest number of LW series, and assessed using four age classes (50-99, 100-199, 200-299, and 300-389 yr). Of particular interest in this analysis was the possible dependence of moisture-signal on tree age. Age-dependence identified by this correlation analysis is residual in the sense that the initial visual screening of archive cores for prominent and variable LW by COFECHA for strong common signal may preferentially eliminate old trees or outer segments of their cores.

Finally, the partial- and total-width chronologies computed with the techniques determined to be optimal were correlated to monthly and seasonal climate data over the full instrumental period to characterize the general climate sensitivity of partial-width indices in the study area.

\section{RESULTS AND DISCUSSION}

\section{LW Chronology Strength}

The common growth-signal in the LW and $\mathrm{LW}_{\mathrm{a}}$ indices is considerably lower than that in EW and TW at the four sites, as measured by the effective chronology signal $\left(\overline{\mathrm{r}}_{\text {eff }}\right)$ and EPS statistics (Table 2). Statistic $\overline{\mathrm{r}}_{\text {eff }}$, which is roughly analogous to a mean between-tree correlation, ranges from 0.33 to 0.46 for the two types of LW index, compared with $0.56-0.62$ for TW index and $0.58-0.65$ for EW index. The results indicate a systematically noisier common signal in LW than in EW, and further that the common signal in TW is degraded somewhat by the noise in the LW. The weaker common signal in $\mathrm{LW}$ and $\mathrm{LW}_{\mathrm{a}}$ translates to a smaller EPS and indicates the need for a greater sample-size requirement to capture the population growth signal. For the four sites studied, 8 11 trees comprise an adequate sample size for adjusted-LW, while only 4-5 trees are required for EW. The difference in signal strength at site DCM leads to a difference in the length of usable site chronology (e.g. for climatic reconstruction) of 97 years.

\section{Treatment of False Latewood Band}

The MB2001 marking rule yielded higher correlations than the ST2009 rule at three sites for correlation of $\mathrm{LW}_{\mathrm{a}}$ with summer precipitation, with a maximum difference of 0.082 (site FSM, site-level adjustment version; Table 3). The consistency in sign of the change in correlation 
Table 2. Summary statistics of common-growth signal strength in total- and partial-width chronologies at four tree-ring sites. Analysis uses version of $\mathrm{LW}_{\mathrm{a}}$ by MB2001 marking rule.

\begin{tabular}{|c|c|c|c|c|c|c|c|}
\hline \multirow[b]{2}{*}{ Site } & \multirow[b]{2}{*}{ Type $^{\mathrm{a}}$} & \multirow[b]{2}{*}{$\overline{\mathrm{r}}_{\mathrm{eff}}^{\mathrm{b}}$} & \multicolumn{2}{|c|}{ No. of Trees ${ }^{c}$} & \multicolumn{3}{|c|}{ Year $^{\mathrm{d}}$} \\
\hline & & & Max & Crit & First & Last & Crit \\
\hline DCM & TW & 0.62 & 35 & 4 & 1654 & 2008 & 1668 \\
\hline DCM & EW & 0.64 & 35 & 4 & 1654 & 2008 & 1667 \\
\hline DCM & LW & 0.42 & 35 & 8 & 1654 & 2008 & 1764 \\
\hline DCM & $\mathrm{LW}_{\mathrm{a}}$ & 0.42 & 35 & 8 & 1654 & 2008 & 1763 \\
\hline FSM & TW & 0.60 & 49 & 4 & 1601 & 2008 & 1627 \\
\hline FSM & EW & 0.65 & 49 & 4 & 1601 & 2008 & 1627 \\
\hline FSM & LW & 0.39 & 49 & 9 & 1601 & 2008 & 1641 \\
\hline FSM & $\mathrm{LW}_{\mathrm{a}}$ & 0.38 & 49 & 10 & 1601 & 2008 & 1646 \\
\hline PRM & TW & 0.58 & 39 & 5 & 1607 & 2008 & 1676 \\
\hline PRM & EW & 0.58 & 39 & 5 & 1607 & 2008 & 1676 \\
\hline PRM & LW & 0.46 & 38 & 7 & 1607 & 2008 & 1684 \\
\hline PRM & $\mathrm{LW}_{\mathrm{a}}$ & 0.43 & 38 & 8 & 1607 & 2008 & 1688 \\
\hline SLC & TW & 0.56 & 44 & 5 & 1632 & 2009 & 1745 \\
\hline SLC & EW & 0.65 & 44 & 4 & 1632 & 2009 & 1723 \\
\hline SLC & LW & 0.33 & 40 & 12 & 1632 & 2009 & 1809 \\
\hline SLC & $\mathrm{LW}_{\mathrm{a}}$ & 0.34 & 40 & 11 & 1632 & 2009 & 1792 \\
\hline
\end{tabular}

${ }^{a}$ Chronology type: total width (TW), earlywood width (EW), latewood width (LW), or adjusted latewood width ( $\left.\mathrm{LW}_{\mathrm{a}}\right)$.

${ }^{\mathrm{b}}$ Effective chronology signal, as defined in text.

${ }^{\mathrm{c}}$ Maximum number of trees in any year (Max) and number of trees (Crit) needed for the critical expressed population signal (EPS) threshold of 0.85 .

${ }^{\mathrm{d}}$ First and last year with any tree-ring data and critical year (first year with EPS $\geq 0.85$ ).

suggests the MB2001 as the preferred marking rule if the objective is summer-precipitation reconstruction. However, a test of difference of correlation (Snedecor and Cochran 1989) indicates that the difference of 0.082 is not statistically significant at $\alpha=0.05$. For the listed correlation of $r=$ 0.51 at site FSM by the ST2009 marking rule, the correlation would need to be higher than $r=0.68$ by the MB2001 rule for the difference in $r$ to be significant at $\alpha=0.05$. We also note for all four sites the ST2009 rule gives slight improvement over MB2001 in correlation of cool-season precipitation with EW. Perhaps some additional seasonal climate information, as yet unidentified,

Table 3. Pearson correlation coefficients of partial-width chronologies with seasonal precipitation, 1896-2008. All coefficients significant at the $99.9 \%$ confidence level.

\begin{tabular}{|c|c|c|c|c|c|c|c|}
\hline \multirow[b]{2}{*}{ Type $^{\mathrm{a}}$} & \multirow[b]{2}{*}{ Measurement ${ }^{\mathrm{b}}$} & \multirow[b]{2}{*}{ Adjustment } & \multicolumn{5}{|c|}{ Site $^{\mathrm{c}}$} \\
\hline & & & DCM & FSM & PRM & SLC & Average \\
\hline EW & MB2001 & N/A & 0.603 & 0.687 & 0.560 & 0.727 & 0.710 \\
\hline EW & ST2009 & N/A & 0.616 & 0.717 & 0.680 & 0.730 & 0.744 \\
\hline $\mathrm{LW}_{\mathrm{a}}$ & MB2001 & Site & 0.636 & 0.592 & 0.502 & 0.549 & 0.725 \\
\hline $\mathrm{LW}_{\mathrm{a}}$ & MB2001 & Core & 0.624 & 0.580 & 0.520 & 0.547 & 0.724 \\
\hline $\mathrm{LW}_{\mathrm{a}}$ & ST2009 & Site & 0.606 & 0.510 & 0.542 & 0.501 & 0.662 \\
\hline $\mathrm{LW}_{\mathrm{a}}$ & ST2009 & Core & 0.595 & 0.499 & 0.540 & 0.503 & 0.653 \\
\hline
\end{tabular}

${ }^{a}$ Chronology type: earlywood width (EW) and adjusted latewood width $\left(\mathrm{LW}_{\mathrm{a}}\right)$.

${ }^{\mathrm{b}}$ Marking rule used to identify boundary between earlywood and latewood, as described in text and illustrated in Figure 1.

${ }^{c}$ Correlations of partial-width index chronologies from individual sites and the average of the four sites with regional-average precipitation totals for their corresponding seasons (October-April for EW, July-August for $\mathrm{LW}_{\mathrm{a}}$ ). 
is present in the discontinuous series of falselatewood band widths. Including that band in the LW degrades the LW signal for summer precipitation, whereas including the band in the EW degrades the EW signal for cool-season precipitation. Including a dummy variable of false ring presence or absence might improve calibration and verification statistics in regression-based climate reconstruction, as in Wimmer et al. (2000).

Practically, the choice of one marking rule over another has greatest implications for tree-ring collections with a high frequency of false rings such as the specimen illustrated in Figure 1. Numerous reports have focused on the meteorological and climatic significance of false rings, as reviewed in part by Edmondson (2010). Further investigations are needed in the Southwest, but the available field-based observations of tree phenology from this area suggest that false rings form during the pre-monsoon May-June drought that is characteristic of the region's climate (Baisan and Swetnam 1994; Fritts 2001). As early as 1919, Douglass published this hypothesis, also noting that "double" rings were most common in years of exceptionally poor snowpack. If the timing of false ring formation does indeed correspond to the period leading up to monsoon onset, these phenomena provide an advantageous anatomical delimiter for the growth that occurs during the monsoon months.

The choice of marking rule for segmenting earlywood and latewood likewise was found to make no statistically significant difference to the $\delta^{13} \mathrm{C}$ values. Latewood cellulose segmented by the MB2001 rule produced average $\delta^{13} \mathrm{C}$ values that were highly correlated $(\mathrm{r}=0.964)$ with those developed from latewood segmented by the ST2009 rule (Figure 4). A high correlation was expected because wood samples analyzed by two methods differ only in thickness of the first false ring, if present. As illustrated by error bars in Figure 4, between-tree variations in $\delta^{13} \mathrm{C}$ values exceed those observed between the average values for each rule. The largest between-rule differences in average $\delta^{13} \mathrm{C}$ measurements are about $0.5 \%$, which is somewhat larger than a realistic sample preparation and analysis error of $c a .0 .2-0.3 \%$, but notably less than the range in average $\delta^{13} \mathrm{C}$

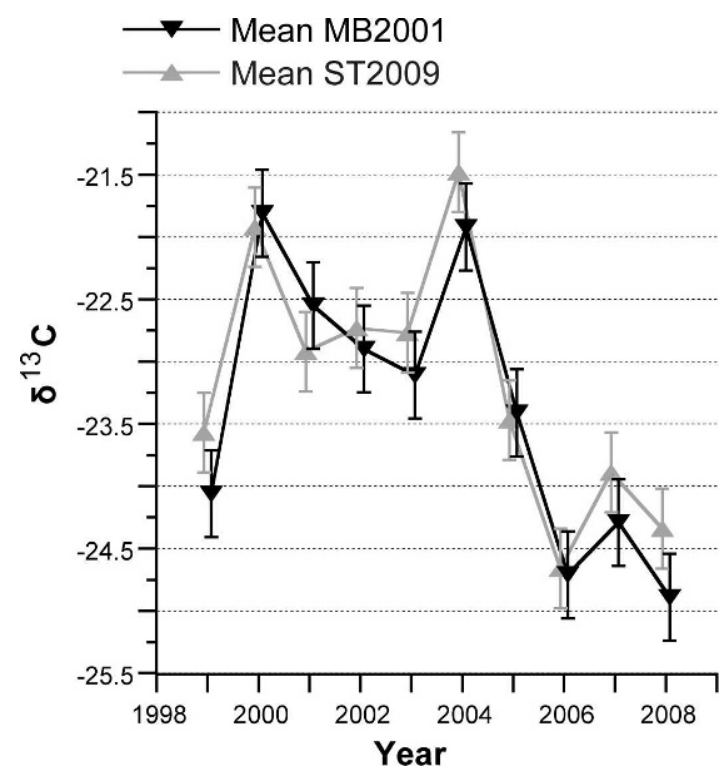

Figure 4. Time plot of $\delta^{13} \mathrm{C}$ from latewood cellulose segmented by MB2001 (black) and ST2009 (gray) marking rules. Triangles represent mean $\delta^{13} \mathrm{C}$ value from four trees per rule. Error bars calculated as \pm 2 standard errors of the mean in each year.

over ten years for either marking rule (e.g. 3.1\% in MB2001). Except for 2001, large differences reflect less negative (less depleted) average $\delta^{13} \mathrm{C}$ in ST2009 than in MB2001. This direction of bias, observed in 25 of the 37 individual comparisons, is consistent with the false latewood band being included in latewood by the ST2009 rule, because the band is presumed to form in a period of water stress contributing to less negative $\delta^{13} \mathrm{C}$.

\section{LW Dependence on Antecedent EW}

Adjustment of LW index for dependence on antecedent EW index defaulted to a linear model (no quadratic term) for 208 of the 306 cores analyzed at the four sites. Examples of linear and quadratic fits for two cores at site PRM are shown in Figure 5. The strong dependence of LW index on EW index for these particular cores is notable, as measured by regression $\mathrm{R}^{2}$ exceeding 0.70 . Core PDF19B (Figure 5A) happened to default to a linear model because the quadratic model (not shown) had a negative (though small) coefficient on the squared EW index. Core PDF16B (Figure $5 \mathrm{~B}$ ) is the best example of curvature in LW- 

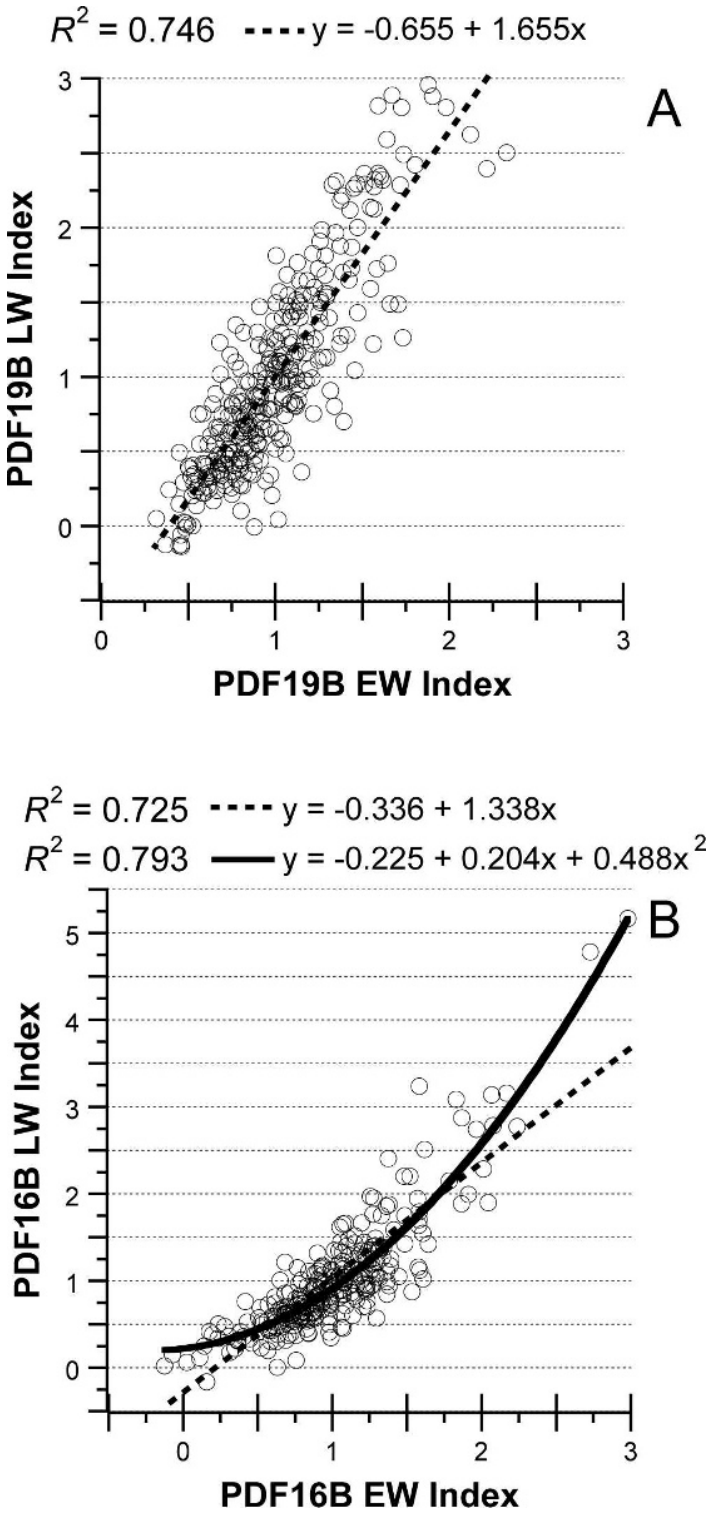

Figure 5. Scatter plots illustrating linear (A) and curvilinear (B) dependence of LW index on EW index for selected cores. Cores identified by axis labels. Regression model coefficients and $\mathrm{R}^{2}$ annotated above.

EW relationship in our data, and even here the addition of the quadratic term adds just seven percent variance explained in regression over the corresponding linear model, marked by the dashed line.

Strength of the LW-EW relationship varies dramatically within and among the four sites, as
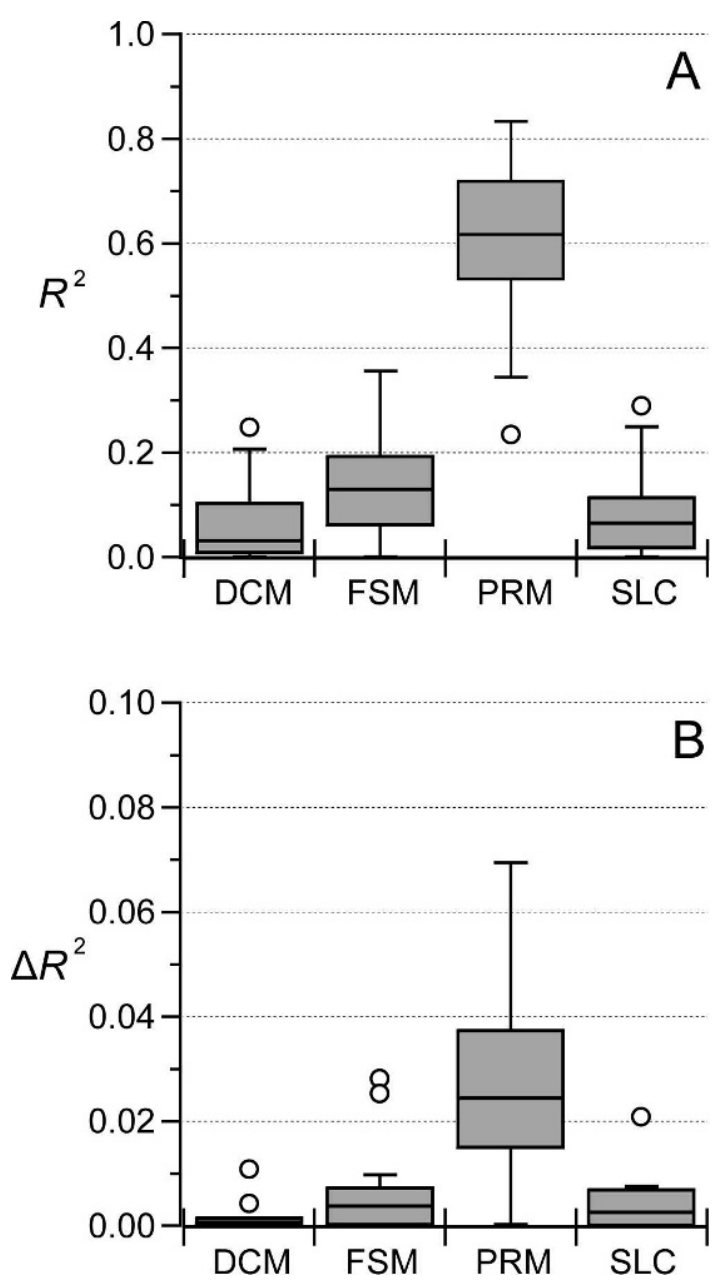

Figure 6. Boxplots summarizing dependence of LW index on EW index. (A) Distribution of $\mathrm{R}^{2}$ from regression of LW index on EW index for cores from the tree-ring sites. Number of cores is 69 (DCM), 94 (FSM), 71 (PRM), and 72 (SLC). (B) Additional $\mathrm{R}^{2}$ for those cores for which a quadratic term has entered the regression. Numbers of cores are 12 (DCM), 23 (FSM), 49 (PRM), and 14 (SLC).

illustrated by a boxplot summary of regression $\mathrm{R}^{2}$ from the adjustment models of 306 cores (Figure 6A). For example, regression $\mathrm{R}^{2}$ at $\mathrm{DCM}$ ranges from 0 to 0.25 while that of PRM varies from 0.24 to 0.83 . PRM appears to differ greatly from the other sites, as indicated by the lack of overlap in the $\mathrm{R}^{2}$ interquartile ranges (Figure 6A). Quadratic adjustment models generally yielded little gain in $R^{2}$ over linear models $\left(\Delta R^{2}\right.$; Figure 6B). The maximum gain for any core was $\Delta \mathrm{R}^{2}=0.07$ at PRM; this extreme example is the 


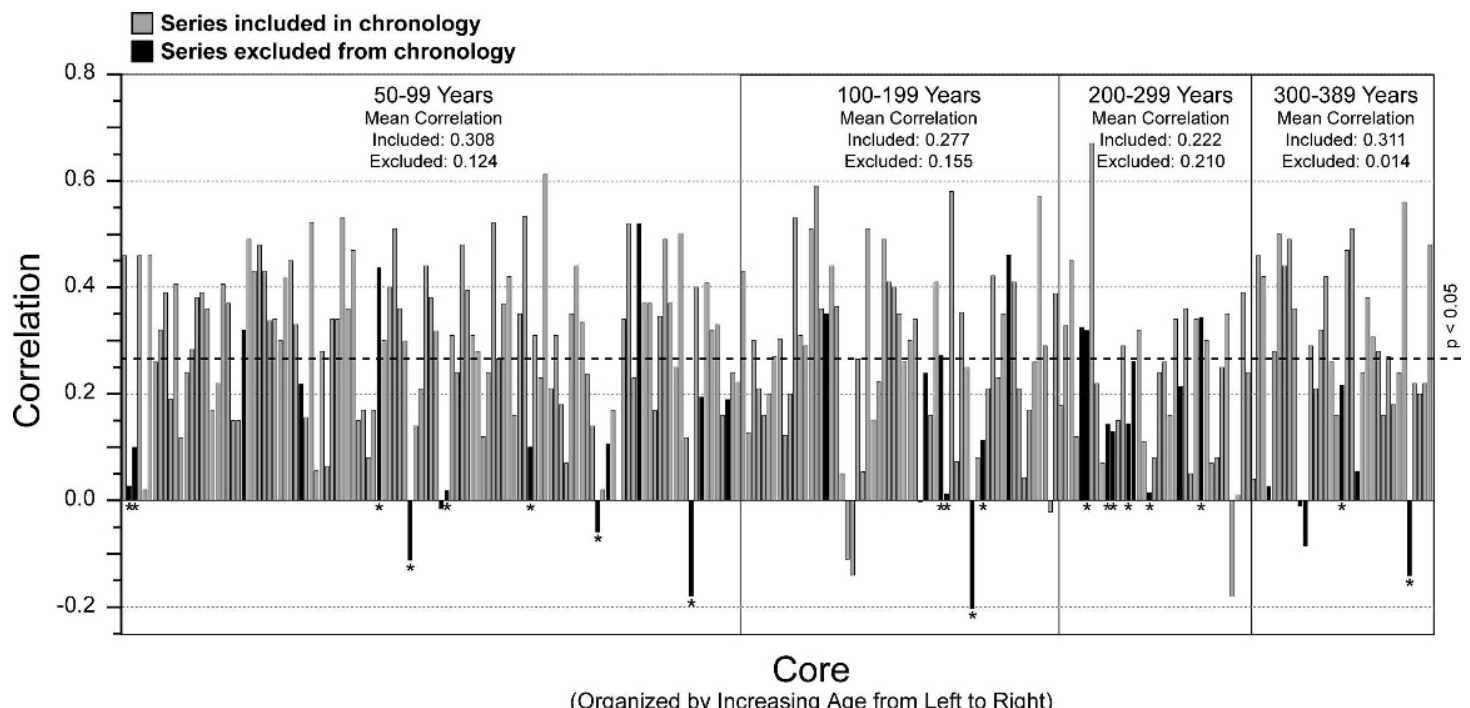

Figure 7. Correlation of July-August precipitation with $\mathrm{LW}_{\mathrm{a}}$ index of all individual cores. Analysis period 1937-1986. Cores ordered left to right in order of increasing age and subdivided into age bins. Grey bars indicate series included in site chronologies. Black bars indicate series excluded from chronologies because of thin and little-varying LW. Asterisks indicate series excluded from site chronologies because of low correlation with site chronology, as determined through analysis with COFECHA (Holmes 1983). Analysis uses version of $\mathrm{LW}_{\mathrm{a}}$ by MB2001 marking rule.

same core used previously in Figure 5B to illustrate curvature in the LW-EW relationship. Median $\Delta \mathrm{R}^{2}$ at the four sites was less than 0.01 , corresponding to less than one percent additional variance explained by the quadratic adjustment model (Figure 6B). Again, PRM appears to differ from the other sites, with $\Delta \mathrm{R}^{2}$ interquartile ranges that do not overlap those from the other sites. The source of this strong seasonal autocorrelation is unknown, but possibly is related to site-specific environmental conditions such as substrate or subsurface hydrology.

Correlations of partial-width site chronologies with precipitation totals, 1896-2008, for their respective seasons are all statistically significant beyond the $99.9 \%$ confidence level (Table 3). Except for DCM, correlations are uniformly higher for the cool season than for summer. The highest correlation at any site is 0.73 for the cool season and 0.64 for summer.

The correlation of $\mathrm{LW}_{\mathrm{a}}$ with summer precipitation appears to be relatively insensitive to whether the adjustment of LW for EW is done at the site-level or core-level: the maximum difference in correlation caused by this factor at any site is less than 0.02 (Table 3), and this difference is not consistent between sites. Despite the lack of evidence for stronger summer-moisture signal with adjustment at the core level, we conclude that this may be the preferred alternative in view of the occasionally large differences in strength of LW-EW relationship among cores. Adjustment at the core level retains the flexibility to evaluate the potential relationship between age and climate sensitivity, and to investigate possible differences in moisture signals related to particular patterns of LW dependence on EW.

\section{Tree Age and Climate Sensitivity}

Comparison of individual core $\mathrm{LW}_{\mathrm{a}}$ index with July-August precipitation for the common period 1937-1986 indicates the strength of summer precipitation signal varies greatly among trees (Figure 7). For cores included in the site chronologies, no systematic relationship between tree age and sensitivity emerges and average climate correlation for each of the four age classes is quite similar. The series with segments excluded from the final chronologies because of low interseries correlation or below-zero detrending curves exhibit lower correlations, on average, with mon- 
soon precipitation than those that were included in the chronologies $(r=0.144$ and 0.280 , respectively). Likewise, no clear age relationship emerges for the excluded individuals, although those excluded from the oldest age class exhibit a notably lower correlation than those included.

As described earlier in this paper and by all NAM tree-ring studies, LW becomes thin and potentially less variable with increasing biological tree age. This seems to be particularly problematic in over-aged or hyper-stressed trees, as was the case in the El Malpais study (Stahle et al. 2009). A caveat to our finding of no clear relationship between age and climate sensitivity is that the samples in our study are relatively young trees (less than 400 years) with relatively robust growth rates. In all cases, the tendency for loss of signal with age might be largely countered by excluding those time-series segments of precisely dated LW whose growth curves drop below some critical threshold or those that have markedly low correlation with the master chronology. As in all related studies, the authors advocate buffering against this potential challenge by including young to middle-aged trees in collections, effectively agestratifying the chronologies progressively through time.

\section{Climate Signal in the Partial-Width Chronologies}

Correlation of adjusted-LW index with summer precipitation increases with averaging over sites (Table 3, last column). For the MB2001/sitelevel version of $\mathrm{LW}_{\mathrm{a}}$ index, the highest correlation for individual sites is 0.636 , whereas the correlation with the four-site average is 0.725 . Correlation of EW index with cool-season precipitation also increases with averaging over sites, but to a lesser degree. The amplified effect for the summer season is probably caused by precipitation anomalies being more spatially heterogeneous with summer convective thunderstorms than with winter cyclones. The precipitation series used for the correlation analysis is a regional average, and anomalies in that series are probably more representative of the anomaly at a given location in winter than in summer. This phenomenon may also contribute to the generally lower correlations

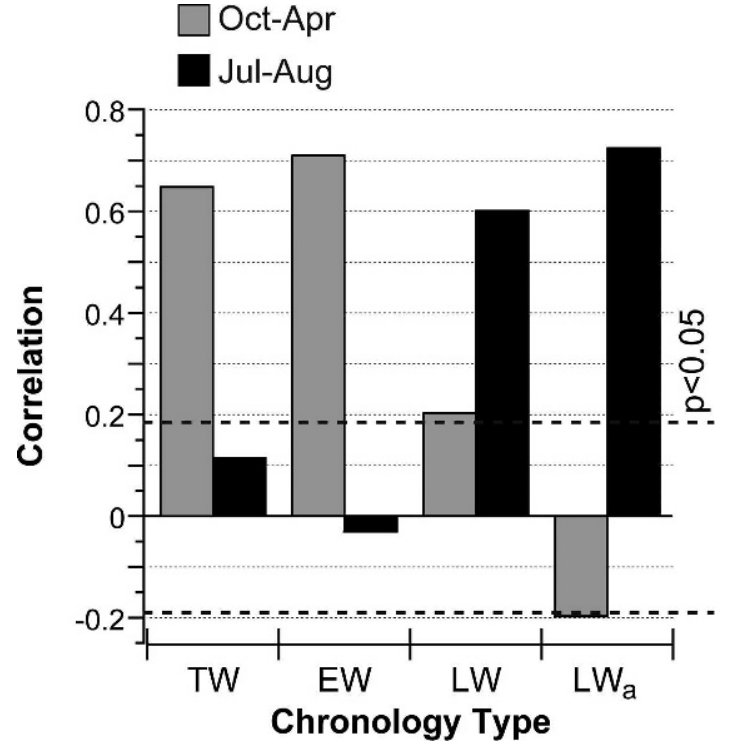

Figure 8. Coefficients for seasonal precipitation correlated with the regional average TW, EW, LW, and $\mathrm{LW}_{\mathrm{a}}$ chronologies for the period 1896-2008. Partial-width components defined by MB2001 marking rule.

for $\mathrm{LW}_{\mathrm{a}}$ index than for $\mathrm{EW}$ index with their respective seasonal precipitation.

The contrasting seasonal-precipitation signals in the various partial-width and total-width components averaged over the four sites are summarized by the bar chart in Figure 8. A summerprecipitation signal is essentially absent in TW index, but is significant in indices of $\mathrm{LW}$ and $\mathrm{LW}_{\mathrm{a}}$. Adjustment of LW index for dependence on antecedent EW index raises the correlation with summer precipitation above 0.70 , and shows that a simple linear regression model using $\mathrm{LW}_{\mathrm{a}}$ averaged over just four sites could explain more than $50 \%$ of the variance of regionally-averaged summer precipitation. Considering the spatial heterogeneity of summer rainfall, this percentage could probably be increased with expanded site coverage.

The bar chart in Figure 8 also points to a spin-off benefit of partial-width measurement, namely improvement over TW in resolution of cool-season precipitation variations. The increased correlation with cool-season precipitation of EW index over TW index shown in Figure 8 amounts to roughly $5 \%$ more variance explained in a regression-based reconstruction model. Ability to separately reconstruct cool-season and warm- 
season precipitation signals will be useful for studying the phenomenon of conditional seasonal precipitation anti-correlation in the NAM region (see Stahle et al. 2009).

\section{CONCLUSION}

Partial-width measurements of Pseudotsuga menziesii have a statistically significant signal for both summer (from $\mathrm{LW}_{\mathrm{a}}$ ) and cool-season (from EW) precipitation in the NAM region. The warmseason signal is not available from TW measurements, and the cool-season signal is weaker in TW measurements. Properly developed $\mathrm{LW}_{\mathrm{a}}$ chronologies can potentially explain more than $50 \%$ of the variance of summer (July + August) precipitation in the study area. This is an important result for future dendroclimatic studies of the NAM, a critical climatic component that influences environment and society in the US Southwest.

Summer-precipitation sensitivity in $\mathrm{LW}_{\mathrm{a}}$ index is robust to the treatments considered here. Excluding the false latewood band from the LW measurements (MB2001) yielded a typically stronger but not significantly different signal for summer-precipitation than those LW measurements that included the false latewood band (ST2009). Likewise, the MB2001 and ST2009 $\delta^{13} \mathrm{C}$ measurements were statistically indistinguishable, but the ST2009 measurements were less negative in 25 of 37 comparisons. In agreement with previous studies (Meko and Baisan 2001; Stahle et al. 2009) removal of the LW dependence on antecedent EW is crucial for extracting the summer-precipitation signal. Our results suggest that site-level LW adjustment (regressing site-level LW index chronology on the site-level EW index chronology) is adequate for these data. However, the strength of the EW-LW relationship varied widely between trees, supporting the argument for adjustment at the core level rather than the site level in chronology development. No strong advantage was found in a quadratic over a linear model for adjustment, but the obvious curvature in scatter plots of LW on EW for a few cores suggests that a flexible model allowing for curvature should also be considered in operational studies.
Dramatic tree-to-tree variations in the strength of summer-precipitation signal suggests that further research is needed to understand how physiographic micro-site, tree phenology, tree age, and other factors influence the tree-growth response to monsoon climate. Further investigations of the false rings' significance are currently being conducted by the authors, including weekly observations of cambial phenology and xylogenesis at the BEA site (Figure 2; Table 1), a reflected light investigation for potential climate signal in primary and secondary peaks of LW density, and the development of false-ring frequency chronologies with methods that are commonly used in studies of fire history.

Our results confirm earlier findings that advanced age may be associated with a loss or reduction in signal strength for summer moisture, but suggest that problematic cores can be effectively identified by weakening of correlation of ring-width patterns of individual trees with the common growth-pattern at the site. Stratification of middle-aged (e.g. 100 to 250 yr-old) trees throughout the length of a chronology is, however, an important consideration in field sampling and chronology development for summer-precipitation reconstruction from $\mathrm{LW}_{\mathrm{a}}$.

This study has focused on one tree species and a fairly limited geographical portion of the area of NAM influence. The study area was intentionally chosen because NAM-related precipitation is highly variable and a major portion of the annual total. More research is needed to determine if our findings can be generalized to other species and geographic and climatic settings in the Southwest. Tree-ring specimens used in this study will be permanently curated in the collection and archives of the Laboratory of Tree-Ring Research. Partial-width measurements prepared for this study will be made available through the International Tree-Ring Data Bank (ITRDB; ttp://www.ncdc.noaa.gov/paleo/treering.html).

\section{ACKNOWLEDGMENTS}

We thank Malcolm Cleaveland, Matthew Therrell, and Jesse Edmondson for their suggestions that improved this manuscript. Funding for 
this study was provided by the National Science Foundation Paleo Perspectives on Climate Change (P2C2) grant \#0823090. Additional support was provided to D. Griffin by the United States Environmental Protection Agency (EPA) under the Science to Achieve Results (STAR) Graduate Fellowship Program, grant \#FP917185. EPA has not officially endorsed this publication and the views expressed herein may not reflect the views of the EPA.

\section{REFERENCES CITED}

Adams, D. K., and A. C. Comrie, 1997. The North American monsoon. Bulletin of the American Meteorological Society 78: 2197-2213.

Babst, F., D. Frank, U. Büntgen, D. Nievergelt, and J. Esper, 2009. Effect of sample preparation and scanning resolution on the blue reflectance of Picea abies. Trace-Tree Rings in Archaeology, Climatology and Ecology, Volume 7. GFZ Scientific Technical Report STR 09/03, Potsdam; pp. 188195.

Baisan, C. H., and T. W. Swetnam, 1994. Assessment of Phenological Growth Patterns in Four Coniferous Species, Rhyolite Canyon, Chiricahua National Monument, Unpublished report, 39 pp. Available from the University of Arizona Laboratory of Tree-Ring Research, Tucson.

Box, G. E. P., and G. M. Jenkins, 1976. Time Series Analysis: Forecasting and Control. Holden Day, San Francisco; 576 pp.

Briffa, K. R., 1984. Tree-Climate Relationships and Dendroclimatological Reconstruction in the British Isles. Ph.D. disseratation, University of East Anglia, Norwich, England, UK.

Briffa, K., and P. D. Jones, 1990. Basic chronology statistics and assessment. In Methods of Dendrochronology: Applications in the Environmental Sciences, edited by E. R. Cook, and L. A. Kairiukstis, pp. 137-152. Kluwer Academic Publishers, Dordrecht.

Carleton, A. M., and D. A. Carpenter, 1990. Mechanisms of interannual variability of the southwest United States summer rainfall maximum. Journal of Climate 3:999-1015.

Castro, C. L., T. B. McKee, and R. A. Pielke, Sr., 2001. The relationship of the North American Monsoon to tropical and north Pacific sea surface temperatures as revealed by observational analyses. Journal of Climate 14:4449-4472.

Cleaveland, M. K., 1986. Climatic response of densitometric properties in semiarid site tree rings. Tree-Ring Bulletin 46: 13-29.

Cleaveland, M. K., 1988. Corrigendum (for "Climatic response of densitometric properties in semiarid site tree rings", TreeRing Bulletin 46:13-29). Tree-Ring Bulletin 48:41-47.

Cleaveland, M. K., D. W. Stahle, M. D. Therrell, J. VillanuevaDiaz, and B. T. Burns, 2003. Tree-ring reconstructed winter precipitation and tropical teleconnections in Durango, Mexico. Climatic Change 59:369-388.

Comrie, A. C., and E. C. Glenn, 1998. Principal componentsbased regionalization of precipitation regimes across the southwestern United States and northern Mexico, with an application to monsoon precipitation variability. Climate Research 10:201-215.

Cook, E. R., and K. Peters, 1981. The smoothing spline: A new approach to standardizing forest interior tree-ring width series for dendroclimatic studies. Tree-Ring Bulletin 41:45-53.

Cook, E. R., S. Shiyatov, and V. Mazepa, 1990. Estimation of the mean chronology. In Methods of Dendrochronology: Applications in the Environmental Sciences, edited by E. R. Cook, and L. A. Kairiukstis, pp. 123-132. Kluwer Academic Publishers, Dordrecht.

Daly, C., M. Halbleib, J. I. Smith, W. P. Gibson, M. K. Doggett, G. H. Taylor, J. Curtis, and P. A. Pasteris, 2008. Physiographically-sensitive mapping of temperature and precipitation across the conterminous United States. International Journal of Climatology. DOI: 10.1002/joc.1688.

D'Arrigo, R. D., and G. C. Jacoby, 1991. A 1000-year record of winter precipitation from northwestern New Mexico, USA: A reconstruction from tree rings and its relationship to El Niño and the southern oscillation. Holocene 1:95-101.

Douglas, M. W., R. Maddox, K. Howard, and S. Reyes, 1993. The Mexican monsoon. Journal of Climate 6:1665-1667.

Douglass, A. E., 1919. Climatic cycles and tree growth: A study of the annual rings of trees in relation to climate and solar activity. Carnegie Institute of Washington 289:18-20.

Edmondson, J. R., 2010. The meterological significance of false rings in eastern redcedar (Juniperus virginiana $\mathrm{L}$.) from the Southern Great Plains, USA. Tree-Ring Research 66:19-34.

Fritts, H. C., 2001. Tree Rings and Climate. Blackburn Press, Caldwell, New Jersey (Originally published 1976, Academic Press London).

Grissino-Mayer, H. D., 1996. A 2129-year reconstruction of precipitation for northwestern New Mexico, USA. In Tree Rings, Environment, and Humanity, edited by J. S. Dean, D. M. Meko, and T. W. Swetnam, pp. 191-204. Radiocarbon, Department of Geosciences, University of Arizona, Tucson.

Grissino-Mayer, H. D., 2001. Assessing crossdating accuracy: A manual and tutorial for the computer program COFECHA. Tree-Ring Research 57:205-221.

Grissino-Mayer, H. D., and T. W. Swetnam, 2000. Centuryscale climate forcing of fire regimes in the American Southwest. The Holocene 10:213-220.

Gutzler, D. S., 2000. Covariability of spring snowpack and summer rainfall across the southwest United States. Journal of Climate 13:4018-4027.

Higgins, R. W., and D. Gochis, 2007. Synthesis of results from the North American monsoon experiment (NAME) process study. Journal of Climate 20:601-1607.

Higgins, R. W., and W. Shi, 2000. Dominant factors responsible for interannual variability of the summer monsoon in the southwestern United States. Journal of Climate 11:25822606.

Holmes, R. L., 1983. Computer-assisted quality control in treering dating and measurement. Tree-Ring Bulletin 44:69-78.

Liebmann, B., I. Blade, N. A. Bond, D. Gochis, D. Allured, and G. T. Bates, 2008. Characteristics of North American summertime rainfall with emphasis on the monsoon. Journal of Climate 21:1277-1294. 
Leavitt, S. W., C. A. Woodhouse, C. L. Castro, W. E. Wright, D. M. Meko, R. Touchan, D. Griffin, and B. Ciancarelli, 2011. The North American monsoon in the US Southwest: Potential for investigation with tree-ring carbon isotopes. Quaternary International 235:101-107.

Leavitt, S. W., W. E. Wright, and A. Long, 2002. Spatial expression of ENSO, drought, and summer monsoon in seasonal $\delta^{13} \mathrm{C}$ of ponderosa pine tree rings in southern Arizona and New Mexico. Journal of Geophysical Research 107(D18):4349. doi:10.1029/2001JD001312.

Meko, D. M., 1981. Applications of Box-Jenkins Methods of Time-Series Analysis to Reconstruction of Drought from Tree Rings. Ph.D. dissertation, University of Arizona, Tucson.

Meko, D. M., 1997. Dendroclimatic reconstruction with time varying predictor subsets of tree indices. Journal of Climate 10:687-696.

Meko, D. M., and C. H. Baisan, 2001. Pilot study of latewoodwidth of conifers as an indicator of variability of summer rainfall in the North American Monsoon region. International Journal of Climatology 21:697-708.

Ni, F., T. Cavazos, M. K. Hughes, A. C. Comrie, and G. Funkhouser, 2002. Cool-season precipitation in the southwestern USA since A.D. 1000: Comparison of linear and nonlinear techniques for reconstruction. International Journal of Climatology 22:1645-1662.

Panyushkina, I. P., S. W. Leavitt, T. A. Thompson, A. F. Schneider, and T. Lange, 2008. Environment and paleoecology of a 12 ka mid-North American Younger Dryas forest chronicled in tree rings. Quaternary Research 70:433-441.

Ray, A. J., G. M. Garfin, M. Wilder, M. Vasques-Leon, M. Lenart, and A. C. Comrie, 2007. Applications of monsoon research: Opportunities to inform decision making and reduce regional vulnerability. Journal of Climate 20:16081626.

Salzer, M. W., and K. F. Kipfmueller, 2005. Reconstructed temperature and precipitation on a millennial timescale from tree rings in the southern Colorado Plateau, USA. Climatic Change 70:467-487.

Schulman, E., 1942. Dendrochronology in pines of Arkansas. Ecology 23:309-318.

Schulman, E., 1951. Dendrochronology in Big Bend National Park, Texas. Tree-Ring Bulletin 18:18-27.

Schweingruber, F. H., H. C. Fritts, O. U. Bräker, L. G. Drew, and E. Schär, 1978. The X-ray technique applied to dendroclimatology. Tree-Ring Bulletin 38:61-91.

Sheppard, P. R., and A. Wiedenhoeft, 2007. An advancement in removing extraneous color from wood for low-magnification reflected-light image analysis of conifer tree rings. Wood and Fiber Science 39:173-183.

Snedecor, G. W., and W. G. Cochran, 1989. Statistical Methods, 8th ed. Iowa State University Press, Ames, Iowa.

Stahle, D. W., M. K. Cleaveland, H. Grissino-Mayer, R. D. Griffin, F. K. Fye, M. D. Therrell, D. J. Burnette, D. M. Meko, and J. Villanueva Diaz, 2009. Cool and early-warm season precipitation reconstructions over western New Mexico. Journal of Climate 22:3729-3750.
Stahle, D. W., J. Villanueva Diaz, M. K. Cleaveland, M. D. Therrell, G. J. Paull, B. T. Burns, W. Salinas, H. Suzan, and P. Z. Fule, 2000. Recent tree-ring research in Mexico. In Dendrochronología en America Latina, edited by F. A. Roig, pp. 285-306. EDIUNC, Mendoza, Argentina.

Stokes, M. A., and T. L. Smiley, 1996. An Introduction to TreeRing Dating. University of Arizona Press, Tucson; 73 pp. (Originally published 1968, University of Chicago Press, Chicago).

Swetnam, T. W., and J. L. Betancourt, 1998. Mesoscale disturbance and ecological response to decadal climatic variability in the American Southwest. Journal of Climate 11:3128-3147.

Therrell, M. D., D. W. Stahle, M. K. Cleaveland, and J. Villanueva-Diaz, 2002. Warm season tree growth and precipitation over Mexico. Journal of Geophysical Research 107(D14):4205. doi.10.1029/2001JD000851.

Thomas, H., 1962. The meteorological phenomenon of drought in the Southwest. US Geological Survey Professional Paper 37A. United States Government Printing Office, Washington. $43 \mathrm{pp}$.

Touchan, R., C. A. Woodhouse, D. M. Meko, and C. D. Allen, 2010. Millennial precipitation reconstruction for the Jemez Mountains, New Mexico, reveals changing drought signal. International Journal of Climatology. doi:10.1002/joc.2117.

Turrent, C., and T. Cavazos, 2009. Role of the land-sea thermal contrast in the interannual modulation of the North American Monsoon. Geophysical Research Letters 36, DOI:10.1029/2008GL036299.

Villanueva-Diaz, J., D. W. Stahle, B. H. Luckman, J. CeranoParedes, M. D. Therrell, M. K. Cleaveland, and E. CornejoOviedo, 2007. Winter-spring precipitation reconstructions from tree rings for northeast Mexico. Climatic Change 83: 117-131.

Wigley, T. M. L., K. R. Briffa, and P. D. Jones, 1984. On the average value of correlated time series, with applications in dendroclimatology and hydrometeorology. Journal of Climate and Applied Meteorology 23:201-213.

Wimmer, R., G. Strumia, and F. Holawe, 2000. Use of false rings in Austrian pine to reconstruct early growing season precipitation. Canadian Journal of Forest Research 30: 1691-1697.

Winter, C. L., 1976. Relationships among Climate, Tree-Ring Widths, and Grass Production on the Santa Rita Experimental Range. M.S. thesis, University of Arizona, Tucson.

Woodhouse, C. A., and D. M. Meko, 1997. Number of winter precipitation days reconstructed from Southwestern tree rings. Journal of Climate 10:2663-2669.

Zahner, R., 1963. Internal moisture stress and wood formation in conifers. Forest Products Journal 13:240-247.

Zhu, C., D. P. Lettenmaier, and T. Cavazos, 2005. Role of antecedent land surface conditions on North American monsoon rainfall variability. Journal of Climate 18:3104 3121 .

Received 2 March 2011; accepted 10 April 2011. 